\title{
Scabies masquerading as bullous pemphigoid: scabies surrepticius
}

This article was published in the following Dove Press journal:

Clinical, Cosmetic and Investigational Dermatology

23 August 2017

Number of times this article has been viewed

\author{
Philip R Cohen \\ Department of Dermatology, \\ University of California San \\ Diego, La Jolla, CA, USA
}

Correspondence: Philip R Cohen Department of Dermatology, University of California San Diego, 8899 University Center Lane, Suite 350, \#0975, San Diego, CA 92122, USA

Email mitehead@gmail.com
Abstract: Scabies, a parasitic infestation caused by the mite Sarcoptes scabiei, is diagnosed by observing either the mite, its ova, or its excrement. The mite tracts, known as burrows and a characteristic presentation of the pruritic condition, are typically found on the web spaces between the fingers. Other cutaneous lesions include excoriated papules, pustules, and vesicles. However, atypical clinical variants of scabies, such as bullous, crusted, hidden, incognito, nodular, and scalp forms of the parasitic infestation, mimic the morphologic features of other non-parasitic dermatoses. A 76-year-old man presented with pruritic blisters and urticarial plaques that demonstrated not only pathology changes, but direct immunofluorescence also showed findings of bullous pemphigoid. His condition improved, but did not resolve, with topical corticosteroid cream for the management of the primary autoimmune blistering disorder. When other family members subsequently developed scabies, the correct diagnosis for his condition, bullous scabies, was established by demonstrating mites, ova, and scybala on a mineral oil preparation from a skin scraping of a newly appearing burrow. Bullous scabies can masquerade not only clinically, but also both pathologically and immunologically as bullous pemphigoid. Scabies serrupticius is introduced as a unifying term to designate all of the non-classic presentations of S. scabiei mite infestation.

Keywords: bullous, crusted, egg, hidden, incognito, masquerade, mimic, mite, nodular, Norwegian, pemphigoid, Sarcoptes scabiei, scabies, scalp, scybala, surrepticius

\section{Introduction}

Scabies is a parasitic infestation caused by the mite Sarcoptes scabiei..$^{1-7}$ It typically presents with pruritus and mite tracts, referred to as burrows. However, there are several atypical clinical variants of scabies: bullous, crusted, hidden, incognito, nodular, and scalp. ${ }^{2,8-51}$

Bullous scabies is an uncommon clinical presentation of the condition in which the lesions morphologically mimic the autoimmune blistering disorder bullous pemphigoid. ${ }^{8-27}$ A man with bullous scabies is described who presented with pruritic blisters and urticarial plaques that demonstrated not only pathology changes but also direct immunofluorescence findings of bullous pemphigoid; the correct diagnosis was established when other family members developed scabies. The designation scabies surrepticius is introduced to unify the atypical morphologic variants of scabies.

\section{Case report}

A 76-year-old Arabic man presented in April 2017 for evaluation of a pruritic skin eruption of 2 months' duration. His past medical history was significant for abdominal 
aorta aneurysm repair in November 2016. His postoperative course had several complications including repeated femoral artery repairs and infected retroperitoneal hematoma and right groin pseudo-aneurysm. In February 2017, cultures were performed; Morganella morganii and Candida albicans grew from the hematoma and M. morganii and Porphyromonas spp. grew from the pseudo-aneurysm.

He returned to the operating room for additional surgeries; a wound vac was placed on his right groin to promote second intention healing. He also received several systemic antibiotics and fluconazole intravenously. On March 4, 2017, he was discharged to a skilled nursing facility; he was being treated with intravenous daptomycin, ertapenem, and linezolid.

Within 1 week of his arrival to the skilled nursing home, he developed an itchy red rash on his chest and abdomen. A drug eruption, from his antibiotics, was suspected and daptomycin and linezolid were discontinued on March 20, 2017. His pruritic eruption was unsuccessfully treated with topical application of hydrocortisone $1 \%$ cream.

On March 29, 2017, he returned to the care of his son and wife who were living with him at his home. He was maintained on the ertapenem. His itching and skin lesions persisted. His son, who was asymptomatic, brought his father for evaluation of the persistent pruritus and skin lesions on April 4, 2017.

Cutaneous examination revealed urticarial dermal red plaques on his chest, abdomen, proximal arms, and thighs (Figures 1 and 2). Two isolated tense bullae were also present on his right abdomen and left thigh (Figure 3); there was no involvement of the face, conjunctiva or oral mucosa. His eosinophil count was normal. There were no burrows on the web spaces between his fingers or elsewhere on his body. Skin biopsies for routine hematoxylin and eosin staining were performed from a plaque on his left abdomen and from the edge of the blister on his right abdomen. In addition, a biopsy from the edge of a plaque on his right abdomen was performed for direct immunofluorescence studies.

Microscopic changes of the biopsy from the left abdomen plaque showed a brisk infiltrate in the superficial and deep dermis consisting of lymphocytes and numerous eosinophils. The biopsy from the blister edge on the right abdomen showed similar microscopic changes; in addition, it also demonstrated a subepidermal vesicle with eosinophils in the papillary dermis at the base of the vesicle. No mites were seen in either specimen.

The direct immunofluorescence microscopy revealed linear deposition of $\mathrm{IgG}$ and complement component $\mathrm{C} 3$

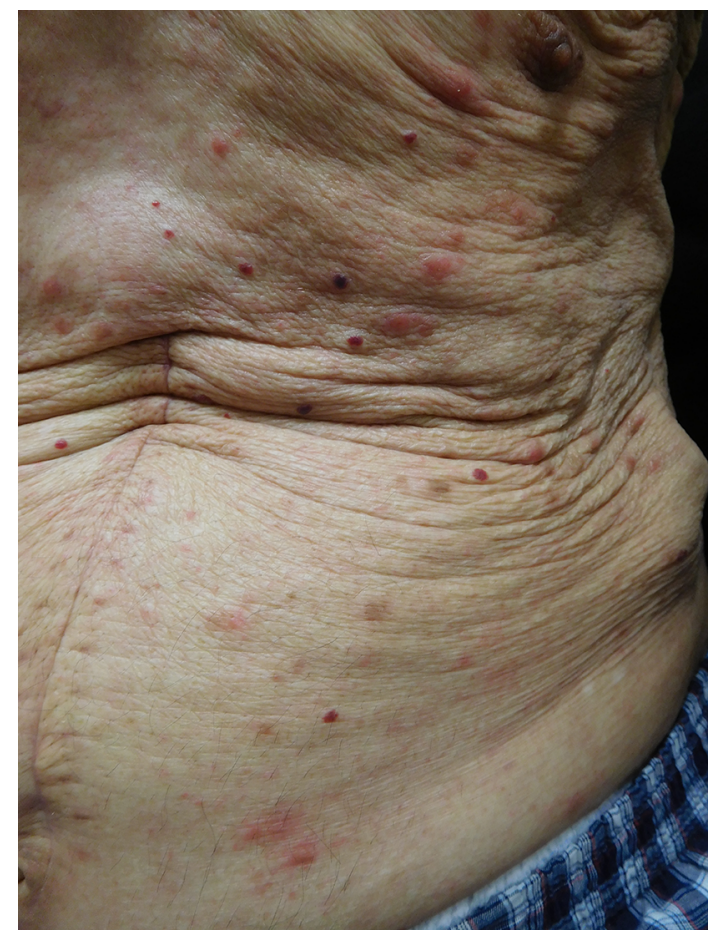

Figure I Scabies masquerading as bullous pemphigoid.

Notes: The chest and abdomen of a 76-year-old man show the new appearance of pruritic pinkish-red dermal plaques. Angiomas, present as dark red nodules, are also numerous.

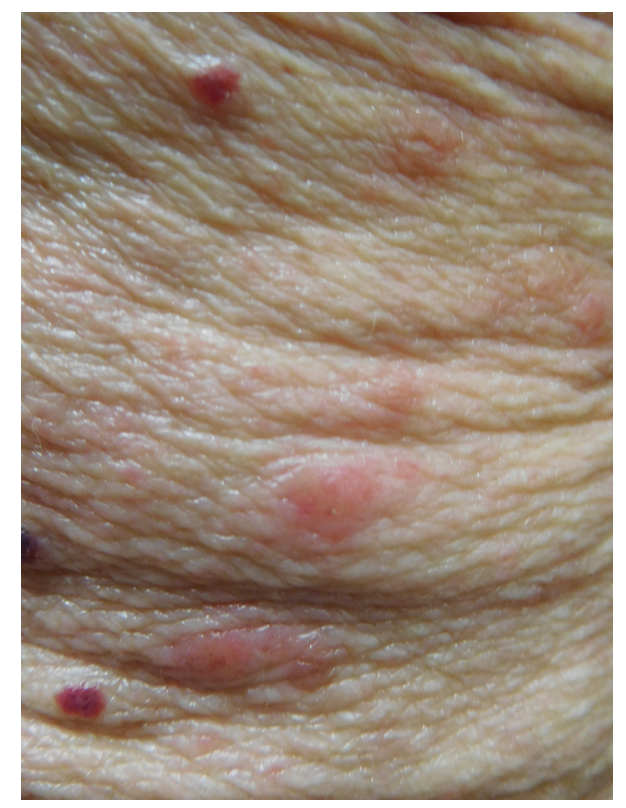

Figure 2 Bullous scabies mimicking bullous pemphigoid.

Notes: A closer view of the scabies lesions presenting as pink-red plaques on the left upper abdomen that mimic the urticarial phase of bullous pemphigoid. Biopsy showed a superficial and deep inflammation containing numerous eosinophils.

along the junction zone of the epidermis and the dermis. Stains for IgA and IgM were negative. These positive direct immunofluorescence findings were consistent with bullous pemphigoid. Additional laboratory studies (such as indirect 


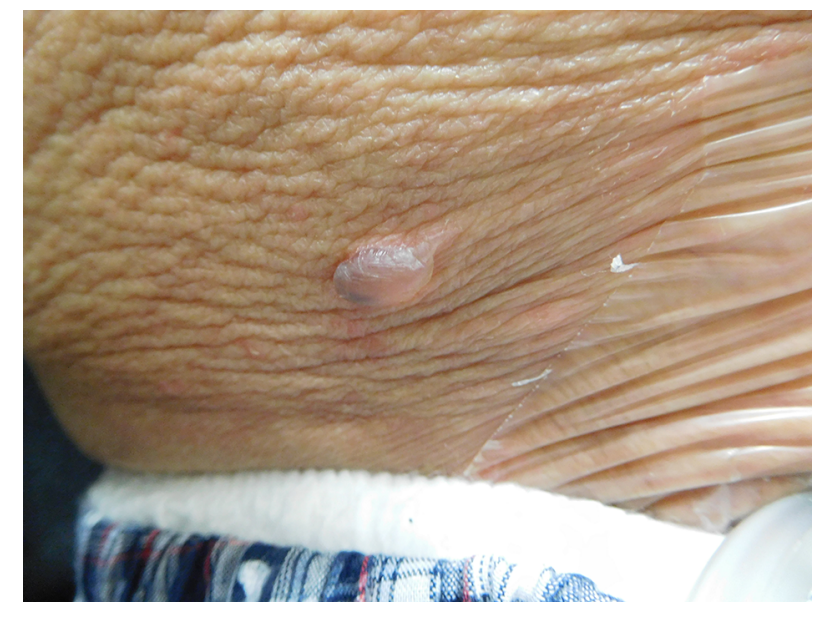

Figure 3 Scabies surrepticius masquerading as bullous pemphigoid. Notes: A closer view of the scabies lesion on the right lower abdomen; it presents as a tense blister. Biopsy showed a sub-epidermal blister with eosinophils not only in the papillary dermis beneath the base of the vesicle, but also in the superficial and deeper dermis.

immunofluorescence and Western blot analysis or enzymelinked immunosorbent assays for circulating antibodies to bullous pemphigoid antigen 180 or bullous pemphigoid antigen 230) were not performed.

Correlation of the clinical symptoms and lesion morphology, pathologic findings, and direct immunofluorescence staining suggested a diagnosis of bullous pemphigoid. He still had an open wound and was receiving intravenous antibiotics; therefore, systemic corticosteroids were deferred and doxycycline and niacin were recommended. However, he declined this treatment and twice daily topical triamcinolone acetonide $0.1 \%$ cream, in conjunction with oral antihistamines (loratadine $10 \mathrm{mg}$ in the morning and diphenhydramine $12.5 \mathrm{mg}$ each evening), was initiated. Within 1 week, the pruritus ceased and the skin lesions were nearly resolved; he tapered the triamcinolone cream to once daily.

Follow-up on May 1, 2017, showed a new pruritic rash. There were erythematous scaly plaques consistent with dermatitis, on his abdomen and thighs; there were no blisters and no burrows. The application of triamcinolone cream was increased to twice daily and the oral antihistamines were continued.

He returned on May 25, 2017. Since his last visit, his wife and son had developed pruritus. They had been evaluated by their primary care physician and diagnosed with scabies based on their symptoms and the morphology of their skin lesions. They were being treated topically with $5 \%$ permethrin cream.

Cutaneous examination revealed excoriated red papules on the arms and legs, back, buttocks, and groin. In addition, classical-appearing burrows were observed on the web spaces between his fingers; there were no blisters. A mineral oil preparation of a skin scraping from the web space burrows demonstrated not only mites, but also ova and scybala confirming the diagnosis of scabies infestation.

Correlation of his prior presentation and current findings established the diagnosis of bullous scabies. Similar to this patient, the absence of mites on the skin biopsy specimen and the positive direct immunofluorescence consistent with bullous pemphigoid has previously been observed in several patients in whom bullous scabies was subsequently diagnosed. ${ }^{8}$ He was treated topically with $5 \%$ permethrin cream on two occasions, 1 week apart; he also received a single dose of $15 \mathrm{mg}$ of ivermectin. His pruritus and skin lesions all resolved without recurrence.

Written informed consent has been obtained from the patient to have the case details and any accompanying images published.

\section{Discussion}

The primary lesion of scabies is a burrow. It is most commonly found on the web spaces between fingers, flexure surface of the wrists, and areola; other sites include axilla, belt line, buttocks, elbows, genitalia, penis shaft, and umbilicus. Secondary lesions of the infestation include small papules, pustules, vesicles, and excoriations. ${ }^{1}$

The diagnosis of scabies is established by visualizing the mite, the egg, and/or the scybala (excrement) on light microscopy of either a skin scraping or biopsy. ${ }^{52}$ Alternatively, a burrow ink test can also be performed. ${ }^{3}$ Dermoscopy is also a highly sensitive method for diagnosing scabies. ${ }^{53}$

Several investigators have attempted to provide a blood test to diagnose scabies. ${ }^{54}$ Although a serologic test that quantifies the level of IgE antibody to a specific recombinant allergen of S. scabiei (rSar s 14.3) has been developed, it is not routinely being used for diagnosis. ${ }^{55}$ Recent advances in the noninvasive diagnosis of scabies include the use of videodermatoscopy, in vivo reflectance confocal microscopy, and optical coherence tomography. ${ }^{56}$

Bullous scabies was originally described in 1974 by a dermatologist in Houston, Texas - Samuel F Bean, MD - to whom a 22-month-old boy with a 2-month history of a generalized pruritic eruption whose lesions on the hands, thighs, and feet had become bullous had been referred to be evaluated for pemphigus or bullous pemphigoid. Dr Bean was unsuccessful in demonstrating a mite from the child. However, his examination of the boy's parents showed an eruption typical of scabies and all were successfully treated topically with 
$1 \%$ gamma benzene hexachloride. ${ }^{13}$ Similar to this boy, the correct diagnosis of bullous scabies was considered in the reported patient and other affected individuals after family members presented with classical scabies symptoms and lesions. ${ }^{14,19}$

Bullous scabies is a rare presentation of the mite infestation. ${ }^{8-27}$ Including the patient in this report, bullous scabies has been described in 46 individuals: 31 men $(69 \%$ of patients) and 14 women ( $31 \%$ of patients). ${ }^{8,25}$ The gender was not described in one child. ${ }^{25}$

The onset age of bullous scabies ranged from 1 to 89 years; the median is 70 years. Similar to the reported patient, the condition most commonly appeared in the seventh decade in 39\% of individuals ( 18 of 46 patients). Nearly two-thirds of the individuals who presented with bullous scabies ( 29 of 46 patients, $63 \%$ ) were older than 60 years; only $17 \%$ of the individuals ( 8 of 46 patients) were less than 30 years. . $13,16,22,25,27^{2}$

Tense vesicles most frequently occur on the arms, legs, and trunk; they may also be generalized in distribution. Less common sites include the genitals, inguinal folds, thighs, buttocks, feet, and neck. Blisters have not been described on either the face or the mucosa in patients with bullous scabies. ${ }^{8}$

The lesions mimic bullous pemphigoid not only clinically but also histologically. Microscopic examination demonstrates subepidermal blisters with eosinophilic dermal inflammation. Mites may also be present in the lesions. ${ }^{8,16,18-20}$

Direct immunofluorescence studies, similar to those of the reported patient, may show features characteristic for bullous pemphigoid with IgM and complement deposition along the basement membrane of the blister; indeed, $58 \%$ of bullous scabies patients (19 of 33 evaluated) had positive direct immunofluorescence studies. ${ }^{8,16,18,20,23}$ Serology evaluation for indirect immunofluorescence testing was only positive in $21 \%$ of bullous scabies patients (five of 24 evaluated) ${ }^{8,23}$ However, in a very small number of individuals, a scabies infestation has subsequently been followed by the development of bullous pemphigoid. ${ }^{57-59}$

The pathogenesis for the development of blisters in patients with bullous scabies remains to be established. Hypotheses include infection-associated, mite-induced basement membrane zone-related, and other etiologies. In bullous scabies patients with lesions that are either infected or impetiginized with Staphylococcus aureus, the mechanism of blister formation may be similar to that observed in individuals with bullous impetigo. ${ }^{23,24}$

Alteration of the basement membrane zone between the epidermis and dermis, secondary - directly or indirectly to the scabies mite, has also been postulated as an etiology for the blisters in patients with bullous scabies. The presence of mites in the blisters supports this theory; ${ }^{14}$ indeed, direct injury to this region by the mite has been suggested. ${ }^{8}$ Enzymes secreted by the mite may result in lytic destruction of the basement membrane and the subsequent production of bullous pemphigoid-like antigens; bullous pemphigoid antibodies, elicited by the antigens, initiate autoimmune-related events such as activation of the complement cascade, release of protease enzymes, and blister formation..$^{23}$ Alternatively, as the result of antigen mimicry, scabies mite proteins may cross-react with the basement membrane antigens and result in bullous pemphigoid antibody or bullous pemphigoid-like autoantibodies production, immune reaction activation, and blister formation. ${ }^{23}$

Other hypotheses for bullous scabies-associated blisters' formation include an id reaction or autoeczematization to the scabies mite..$^{24}$ In addition, a type I immune response to an antigen from the saliva of the scabies mite has been proposed. ${ }^{22}$ Also, it has been speculated that the persistent scabies infestation results in activation of Th2 cells, which leads to an increase in the level of IL-5 and the number of circulating eosinophils, which subsequently causes blister formation. ${ }^{12}$

Bullous scabies is treated in the same manner as nonbullous scabies. Many patients are successfully treated with topical antiscabetic medications. The reported patient received not only topical ( $5 \%$ permethrin cream) but also systemic (ivermectin) treatment. Other individuals with bullous scabies were also treated with ivermectin. ${ }^{10,11,16}$

The differential diagnosis of bullous scabies in childhood includes atopic dermatitis, ecthyma, impetigo, papular urticaria, psoriasis, seborrheic dermatitis, and varicella. In adults, bullous scabies not only masquerades clinically, by light microscopy and immunopathology as bullous pemphigoid, but also other dermatoses. It can mimic acquired epidermolysis bullosa, acute contact dermatitis, arthropod bite reaction, bullous impetigo, and pemphigus..$^{8-27}$

Similar to the reported patient, bullous scabies often presents in patients with a pruritic dermatosis who have previously been treated with systemic ${ }^{10,17-20}$ and/or topical ${ }^{15,20}$ corticosteroid. This variant of the infestation is known as scabies incognito. The corticosteroid alters the characteristic symptoms and lesions of the mite infestation. In addition to bullous pemphigoid-like lesions of bullous scabies, the morphology of infectious lesions in patients with scabies incognito can mimic acute skin rejection (in vascularized composite allotransplantation), arthropod bites, contact dermatitis, eczematous dermatitis, impetigo, Langerhans 
cell histiocytosis, psoriasis, seborrheic dermatitis, subcorneal pustular dermatosis, and urticaria pigmentosa. ${ }^{2,15,30,36,42-45}$

Crusted scabies, also referred to as Norwegian scabies, presents as hyperkeratotic plaques containing large numbers of mites. It is often found in patients who are immunosuppressed (such as individuals who have acquired HIV or have received a solid organ transplant). In children, crusted scabies is most commonly observed in individuals with Down's syndrome; other predisposing factors include autoimmune disorders (such as systemic lupus erythematosus) immunodeficiency (such as chronic mucocutaneous candidiasis and congenital T-cell deficiency), inherited bullous disorders (such as dystrophic epidermolysis bullosa), protein and vitamin deficiency (such as kwashiorkor and vitamin A deficiency), and recipients of oral or topical corticosteroids. Other conditions that crusted scabies mimics include erythroderma, Darier's disease, drug eruption, eczema, lichen planus, lymphoma, pityriasis rubra pilaris, and psoriasis. ${ }^{15,28-40}$

Nodular scabies is a variant of the infestation that presents as pruritic reddish brown papules and nodules that are typically located in covered areas of the body (such as the axilla, buttocks, groin, and male genitalia - penis and scrotum). It is considered to be a hypersensitivity reaction to the products of S. scabiei since the mite is usually not present in the lesions. It has been noted with increased frequency in immunosuppressed individuals. Other conditions mimic the morphology (such as histiocytosis and lymphoma) or pathology (such as arthropod bite reaction and pseudolymphoma) of nodular scabies. ${ }^{30,46-49}$

Hidden scabies (also referred to as unrecognized scabies) was described in a 57-year-old woman. She had lesions that appeared to represent an atypical eczema: itchy erythematous macules and papules - some of which were serous - on her thighs, arms, and back. There were no burrows and the lesions spared her interdigital fingers and genitalia. Lesion skin biopsies were negative for mites and scybala. However, she was empirically treated for scabies with topical crotamiton for 5 days and all of her symptoms and lesions resolved within 2 weeks. Polymerase chain reaction on cutaneous scales from the woman was performed to amplify S. scabiei DNA; subsequently, enzyme-linked immunosorbent assay detection of mite DNA was positive before and negative 2 weeks after treatment. ${ }^{41}$

Concurrent systemic disorders or infection or both can alter the clinical presentation of scabies. Scabies can occur in individuals with other conditions such as cutaneous T-cell lymphoma, ${ }^{60}$ dystrophic epidermolysis bullosa, ${ }^{26}$ psoriasis, ${ }^{34,35}$ and systemic lupus erythematosus. ${ }^{29,45,51}$ In addition, scabies lesions can become secondarily infected with either bacteria (such as S. aureus or Streptococcus pyogenes $)^{6,20,23,61,62}$ or herpes simplex virus. ${ }^{63}$ In addition, scabies infestation has masqueraded as ecchymoses, chronic urticaria, dermatitis herpetiformis, histiocytosis, systemic lupus erythematosus, and urticaria pigmentosa. ${ }^{32,44,47-49,64-71}$

Child abuse was suspected in an untreated 6-year-old boy who was admitted with a 10-day history of diffuse lesions that resembled bruises; during the hospitalization mites and eggs were demonstrated in scrapings from the lesions that had subsequently become pruritic and all of the lesions resolved after two applications of topical 5\% permethrin cream and systemic corticosteroids. ${ }^{65}$ A 22-year-old woman with a 3-month history of generalized urticaria (showing temporary improvement after multiple different treatments including topical fluorinated corticosteroids) presented for evaluation; mites and eggs were demonstrated from a scraping of a burrow on her finger and the urticaria resolved within 48 hours after topical scabies treatment with $1 \%$ lindane lotion. ${ }^{69}$ Five patients with pruritic papules and vesicles on their thighs and/ or buttocks were suspected to have dermatitis herpetiformis; however, mites were observed in the stratum corneum of skin biopsies from each person. ${ }^{64}$

Surreptitious refers to misrepresentation of the truth or characterized by fraud. Scabies surrepticius is a comprehensive term that is introduced to designate all of the atypical presentations of S. scabiei infestation (Table 1).,.$^{2-51,64-71}$ In all circumstances, the mite-associated skin lesions masquerade as other dermatoses. A single designation that encompasses all of the unique morphologies, scabies surrepticius, may be more appropriate than the multiple individual categories that currently exist.

\section{Conclusion}

Scabies is diagnosed by observing either the $S$. scabiei mite, or its ova or its excrement. The pruritic condition classically presents with burrows that are often located on the web spaces between the fingers. Other cutaneous lesions include excoriated papules, pustules, and vesicles. Bullous, crusted, hidden, incognito, nodular, and scalp forms of the parasitic infestation are atypical clinical variants of scabies. Each of these subtypes of scabies mimics the morphologic features of other non-parasitic dermatoses. For example - as demonstrated by the reported patient - bullous scabies masquerades not only clinically, but also both pathologically and immunologically as bullous pemphigoid. Scabies serrupticius provides a unifying term to designate all of the non-classic presentations of this mite infestation. 
Table I Scabies surrepticius: subtypes

\begin{tabular}{|c|c|c|}
\hline Subtype & Morphology presentation & Differential diagnosis \\
\hline Bullous [a] & Blisters & $\begin{array}{l}\text { Acquired epidermolysis bullosa, acute contact dermatitis, arthropod } \\
\text { bite reaction, atopic dermatitis, bullous impetigo, bullous pemphigoid, } \\
\text { chronic bullous disease of childhood, ecthyma, epidermolysis bullosa } \\
\text { simplex, papular urticaria, pemphigus vulgaris, psoriasis, seborrheic } \\
\text { dermatitis, varicella }\end{array}$ \\
\hline Crusted $[\mathrm{b}]$ & Diffusely distributed hyperkeratotic plaques and scales & $\begin{array}{l}\text { Erythroderma, Darier's disease, drug eruption, eczema, LCH, lichen } \\
\text { planus, lymphoma, pityriasis rubra pilaris, psoriasis }\end{array}$ \\
\hline Hidden [c] & Serous and non-serous papules and erythematous macules & Atypical eczema \\
\hline Incognito [d] & Macules, papules, nodules, blisters & $\begin{array}{l}\text { Acute skin rejection of vascularized composite allotransplantation, } \\
\text { arthropod bites, bullous pemphigoid, contact dermatitis, eczematous } \\
\text { dermatitis, impetigo, dermatomyositis, LCH, psoriasis, seborrheic } \\
\text { dermatitis, subcorneal pustular dermatosis, UP }\end{array}$ \\
\hline Nodular [e] & Reddish to brown, 2-20 mm, nodules & Histiocytosis, lymphoma, UP \\
\hline Scalp $[f]$ & Asymptomatic fine scaling or painful erythematous plaques & Psoriasis, seborrheic dermatitis \\
\hline
\end{tabular}

Other

DH-like [g]

Papules, vesicles, and crusted erosions

$\mathrm{DH}$

Ecchymoses [h] Ecchymotic and petechial skin changes

Child abuse

LCH-like [i] Papules (red-brown-orange) or eczematous eruption

SLE-like [j] Erythematous scaly plaques in the malar area

Urticaria [k] Edematous plaques (hives) and dermographism

UP-like [l] Papules (red-brown) with positive Darier's sign

Histiocytosis

SLE

Urticaria

UP

Notes: [a] This subtype is predominantly observed in older men on the trunk and extremities. It mimics bullous pemphigoid (not only the clinical morphology, but also the pathology, direct immunofluorescence, and occasionally indirect immunofluorescence) and other bullous dermatoses. ${ }^{8-27}$ [b] This subtype is also referred to as hyperkeratotic or Norwegian scabies. It is more common in immunosuppressed hosts. There is a heavy infestation of mites and this variant of scabies is very contagious. ${ }^{15,28-40}$ [c] This subtype is also referred to as unrecognized scabies; polymerase chain reaction of cutaneous scales positive for Sarcoptes scabiei DNA. It presented as an atypical eczema in a woman following automobile accident. ${ }^{41}$ [d] This subtype of scabies occurs after the treatment of the scabies patient with topical or systemic corticosteroids; the corticosteroid treatment masks the typical symptoms and signs of the mite infestation. The morphology mimics not only bullous dermatoses but also several other skin conditions. $2,15,30,36,42-45$ [e] The pruritic nodules (reddish to brown and 2 to $20 \mathrm{~mm}$ ) are often located on the axilla, buttocks, genitalia, groin, penis, and scrotum. The pruritic lesions are a hypersensitivity reaction and typically do not contain mites; however, they can persist for weeks to months following the successful treatment of the infestation. ${ }^{30,46-49}$ [f] This subtype can present as asymptomatic (fine scales) or symptomatic (erythematous plaques) lesions. It is more common in infants, children, and the elderly. It also occurs in individuals with congenital or acquired deficiency of their immune system including patients with the following conditions: AIDS, acute lymphoblastic leukemia, adult T-cell leukemia/lymphoma, dermatomyositis, systemic lupus erythematosus, and Trisomy $21 .{ }^{29,31,33,36,50,51}[\mathrm{~g}]$ This subtype presents as pruritic papules, vesicles, and crusted erosions that occur in the sacral and gluteal regions ${ }^{64}[\mathrm{~h}]$ This subtupe presents as ecchymotic and petechial skin changes that mimic child abuse. ${ }^{65}[\mathrm{i}]$ This subtype usually presents in infants and children as either red-brown-orange papules or an eczematous eruption. The pathology of the lesions can also mimic that of Langerhans cell histiocytosis. Some patients have received treatment with antineoplastic agents prior to the establishment of the correct diagnosis. ${ }^{32,49,66,67}$ [j] A I5-year-old Caucasian girl presented with a family history (paternal uncle) of systemic lupus erythematosus, possible photosensitivity, painful mouth ulcers, and pleuritic chest pain. Cutaneous examination showed diffuse dermatographia, blanching linear excoriations on the lower thigh and mid-to-lower scapula, erythematosus scaly plaques in the malar area, the nasolabial folds and frontal area and between the fingers, and a small ulcer of the buccal mucosa. There was a murmur over the precordium and echocardiogram showed mitral valve prolapse. Lab abnormalities included normocytic normochromic anemia (hematocrit was 33\%), iron studies consistent with iron deficiency anemia, and antinuclear antibody was positive at a 1:320 titer, in a speckled pattern; anti-Smith, anti-double strand DNA, and anti-ribonucleoprotein antibodies were negative. Direct microscopic examination of a fresh skin preparation was positive for $\mathrm{S}$. scabiei. The patient's manifestations all promptly resolved after treatment with permethrin and she has remained asymptomatic. ${ }^{68}[\mathrm{k}] \mathrm{The}$ prominent features of this subtype are edematous plaques (hives) and dermographism; however, there may also be burrows on fingers and papules on areola, elbows, and buttocks. ${ }^{69}[1]$ This subtype typically occurs in infants. The pruritic red-brown lesions become swollen, itchy, and erythematous after being stroked; this is referred to as a positive Darier's sign and is observed after stroking lesions on the skin of a person with systemic mastocytosis or urticaria pigmentosa. ${ }^{44,47,48,70,71}$

Abbreviations: DH, dermatitis herpetiformis; LCH, Langerhans cell histiocytosis; SLE, systemic lupus erythematosus; UP, urticaria pigmentosa.

\section{Disclosure}

The author reports no conflicts of interest in this work.

\section{References}

1. Chosidow O. Clinical practices. Scabies. N Engl J Med. 2006;354(16): 1718-1727.

2. Yoshinaga E, Oiso N, Kawara S, Kawada A. An adolescent patient with scabies mimicking Gottron papules. Case Rep Dermatol. 2009;2(1): $8-12$.

3. Hengge UR, Currie BJ, Jager G, Lupi O, Schwartz RA. Scabies: a ubiquitous neglected skin disease. Lancet Infect Dis. 2006;6(12):769-779.

4. Heukelback J, Feldmeier H. Scabies. Lancet. 2006;367(9524):1767-1764.

5. Executive Committee of Guideline for the Diagnosis and Treatment of Scabies. Guideline for the diagnosis and treatment of scabies in Japan (third edition): executive committee of guideline for the diagnosis and treatment of scabies. J Dermatol. Epub 2017 May 31.
6. Hardy M, Engelman D, Steer A. Scabies: a clinical update. Aust Fam Physician. 2017;48(5):264-268.

7. Stoffle NN, Cohen PR. Images in clinical medicine. Sarcoptes scabiei infestation. N Engl J Med. 2004;350(22).e20.

8. Luo DQ, Huang MX, Liu JH, Tang W, Zhao YK, Sarkar R. Case report: bullous scabies. Am J Trop Med Hyg. 2016;95(3):689-693.

9. Gutte RM. Bullous scabies in an adult: a case report with review of literature. Indian Dermatol Online J. 2013;4(4):311-313.

10. Galvany Rossell L, Salleras Redonnet M, Umbert Millet P. Sarna ampollosa con respuesta terapéutica a la ivermectina [Bullous scabies responding to ivermectin therapy]. Actas Dermosifiliogr. 2010;101(1):81-84. Spanish.

11. Nakamura E, Taniguchi H, Ohtaki N. A case of crusted scabies with a bullous pemphigoid-like eruption and nail involvement. J Dermatol. 2006;33(3):196-201.

12. Bornhövd E, Partscht K, Flaig MJ, Messer G. Bullöse Krätze und Krätze ausgelöste bullöse pemphigoid [Bullous scabies and scabies-triggered bullous pemphigoid]. Hautarzt. 2001;52(1):56-61. German. 
13. Bean SF. Bullous scabies. JAMA. 1974;230(6):878.

14. Veraldi S, Scarabelli G, Zerboni R, Pelosi A, Gianotti R. Bullous scabies. Acta Derm Venereol. 1996;76(2):167-168.

15. Su WJ, Fang S, Chen AJ, Shan K. A case of crusted scabies combined with bullous scabies. Exp Ther Med. 2015;10(4):1533-1535.

16. Balighi K, Robati RM, Hejazi N. A dilemma: bullous pemphigoid-like eruption in scabies or scabies-induced bullous pemphigoid. Dermatol Online J. 2006;12(4): 13.

17. Viraben R, Dupre A. Scabies mimicking bullous pemphigoid. $J \mathrm{Am}$ Acad Dermatol. 1985;20(1):134-136.

18. Slawsky LD, Maroon M, Tyler WB, Miller OF 3rd. Association of scabies with a bullous pemphigoid-like eruption. J Am Acad Dermatol. 1996;34(5 Pt 2):878-879.

19. Brar BK, Pall A, Gupta RR. Bullous scabies mimicking bullous pemphigoid. J Dermatol. 2003;30(9):694-696.

20. Bhawan J, Milstone E, Malhotra R, Rosenfeld T, Appel M. Scabies presenting as bullous pemphigoid-like eruption. J Am Acad Dermatol. 1991;24(2 Pt 1):179-181.

21. Akin Belli A, Geyik N, Dervis E. A case of bullous scabies misdiagnosed as acquired epidermolysis bullosa. Int J Dermatol. 2015;54(11): e499-501.

22. Maan MA, Maan MS, Sohail AM, Arif M. Bullous scabies: a case report and review of the literature. BMC Res Notes. 2015;8:254.

23. Ostlere LS, Harris D, Rustin MH. Scabies associated with a bullous pemphigoid-like eruption. Br J Dermatol. 1993;128(2):217-219.

24. Ansarin H, Jalali MHA, Mazloomi S, Soltani-Arabshahi R, Setarehshenas R. Scabies presenting with bullous pemphigoid-like lesions. Dermatol Online J. 2006;12(1):19.

25. Guergue Diaz de Cerio O, Gonzalez Hermosa M del R, Ballestero Diez M. Bullous scabies in a 5-year-old child. J Pediatr. 2016;179: 270.e1-271.e1.

26. Ponce-Navarez E, Przybilla B. Bullöse Skabies bei Epidermolysis bullosa hereditaria dystrophica [Bullous scabies in hereditary dystrophic epidermolysis bullosa]. Hautarzt. 1981;32(2):966-997. German.

27. Shahab RK, Loo DS. Bullous scabies. J Am Acad Dermatol. 2003;49(2):346-350.

28. Kulkami S, Shah H, Patel B, Bhuptani N. Crusted scabies: presenting as erythroderma in a human immunodeficiency virus-seropositive patient Indian J Sex Transm Dis. 2016;37(1):72-74.

29. Yee BE, Carlos CA, Hata T. Crusted scabies of the scalp in a patien with systemic lupus erythematosus. Dermatol Online J. 2014;20(10).

30. Orkin M. Today's scabies. JAMA. 1975;233(8):882-885.

31. Lia YC, Teng CJ, Chen PC, Chiou TJ, Liu CY. Unusual scalp crusted scabies in an adult T-cell leukemia/lymphoma patient. Ups J Med Sci. 2011;116(1):77-78.

32. Kartono F, Lee EW, Lanum D, Pham L, Maibach HI. Crusted Norwegian scabies in an adult with Langerhans cell histiocytosis: mishaps leading to systemic chemotherapy. Arch Dermatol. 2007;143(5):626-628.

33. Dourmishev AL, Serafimova DK, Dourmishev LA, Mualla MA, Papaharalambous V, Machevsky T. Crusted scabies of the scalp in dermatomyositis patients: three cases treated with oral ivermectin. Int J Dermatol. 1998;37(3):231-234.

34. Fuchs BS, Sapadin AN, Phelps RG, Rudikoff D. Diagnostic dilemma: crusted scabies superimposed on psoriatic erythroderma in a patient with acquired immunodeficiency syndrome. Skinmed. 2007;6(3): $142-144$.

35. Keipert JA. Norwegian scabies in a girl with psoriasis. Australas $J$ Dermatol. 1986;27(1):29-32.

36. Lehmberg J, Roper B, Omouryi EA, Evangelista M. Skin plaques mimicking psoriasis. J Pediatr. 2015;167(4):937-937.e1.

37. Murugaiyan R, Lakshmanan K, Sengottian B, Karthikeyan K. Crusted scabies presenting as palmoplantar psoriasis in Down's syndrome. Indian Dermatol Online J. 2015;6(2):140-141.

38. Garofalo V, Saraceno R, Milana M, Lenci I, Angelico M, Orlandi A, Bianchi L. Crusted scabies in a liver transplant patient mimicking rupioid psoriasis. Eur J Dermatol. 2016;26(5):495-496.
39. Rudolph RI. Scabies resembling Darier's disease. JAMA. 1982;247(14): 1937.

40. Anolik MA, Rudolph RI. Scabies simulating Darier disease in an immunosuppressed host. Arch Dermatol. 1976;112(1):73-74.

41. Bezold G, Lange M, Schiener R, et al. Hidden scabies: diagnosis by polymerase chain reaction. Br J Dermatol. 2001;144(3):614-618.

42. Karaca S, Kelekci KH, Er O, Pektas B, Gokmen AA. Scabies incognito presenting as a subcorneal pustular dermatosis-like eruption. Turkiye Parazitol Derg. 2015;39(3):244-247.

43. Kanitakis J, Morelon E. Scabies in a bilateral hand allograft recipient: an additional mimicker of acute skin rejection in vascularized composite allotransplantation. Transpl Infect Dis. 2017;19(3).

44. Kim KJ, Roh KH, Choi JH, Sung KJ, Moon KC, Koh JK. Scabies incognito presenting as urticarial pigmentosa in an infant. Pediatr Dermatol. 2002;19(5):409-411.

45. Val-Bernal JF, Gonzalez-Vala MC, Yanez S, Mira C, Martinez-Taboada $\mathrm{V}$, Rodriguez-Valverde V. Atypical scabies in systemic lupus erythematosus. Ann Saudi Med. 1998;18(6):534-536.

46. Ramachandra Reddy D, Ramachandra Reddy P. Nodular scabies: a classical case report in an adolescent boy. J Parasit Dis. 2015;39(3):581-583.

47. Salces IG, Alfaro J, Saenz DE, Santamaria MC, Sanchez M. Scabies presenting as solitary mastocytoma-like eruption in an infant. Pediatr Dermatol. 2009;26(4):486-488.

48. Mauleón-Fernandez C, Sáez-de-Ocariz M, Rodríguez-Jurado R, DuránMcKinster C, Orozco-Covarrubias L, Ruiz-Maldonado R. Nodular scabies mimicking urticarial pigmentosa in an infant. Clin Exp Dermatol. 2005;30(5):595-596.

49. Burch JM, Krol A, Weston WL. Sarcopetes scabiei infestation misdiagnosed and treated as Langerhans cell histiocytosis. Pediatr Dermatol. 2004;21(1):58-62.

50. Duran C, Tamayo L, de la Luz Orozco M, Ruiz-Maldonado R. Scabies of the scalp mimicking seborrheic dermatitis in immunocompromised patients. Pediatr Dermatol. 1993;10(2):136-138.

51. Chan JC, Yap DY, Shea YF, Yuen CK, Yeung CK. A highly contagious psoriasiform eruption on the scalp of a patient with systemic lupus erythematosus. J Clin Rheumatol. 2012;18(3):144-145.

52. Anderson KL, Strowd LC. Epidemiology, diagnosis, and treatment of scabies in a dermatology office. J Am Board Fam Med. 2017;30(1):78-84

53. Park JH, Kim CW, Kim SS. The diagnostic accuracy of dermoscopy for scabies. Ann Dermatol. 2012;24(2):194-199.

54. Arlian LG, Morgan MS. A review of Sarcoptes scabiei: past, present and future. Parasit Vectors. 2017;10(1):297.

55. Jayaraj R, Hales B, Viberg L, et al. A diagnostic test for scabies: IgE specificity for a recombinant allergen of Sarcoptes scabiei. Diagn Microbiol Infect Dis. 2011;71(4):403-407.

56. Micali G, Lacarrubba F, Verzi AE, Chosidow O, Schwartz RA. Scabies: advances in noninvasive diagnosis. PLoS Negl Trop Dis. 2016;10(6): e0004691.

57. Chung SD, Lin HC, Wang KH. Increased risk of pemphigoid following scabies: a population-based matched-cohort study. J Eur Acad Dermatol Venereol. 2014;28(5):558-564.

58. Konishi N, Suzuki K, Yokura Y, Hashimoto T, Takigawa M. Bullous eruption associated with scabies: evidence for scabetic induction of true bullous pemphigoid. Acta Derm Venereol. 2000;80(4):281-283.

59. Huang MX, Li ZS, Luo DQ, Lin Q. Bullous pemphigoid-like eruption subsequent to scabies: bullous scabies or bullous pemphigoid? G Ital Dermatol Venereol. 2015;150(3):337-339.

60. McGregor DH, Yang Q, Fan F, Talley RL, Topalovski M. Scabies associated with radiation therapy for cutaneous T-cell lymphoma. Ann Clin Lab Sci. 2001;31(1):103-107.

61. Bowen AC, Tong SY, Chatfield MD, Carapetis JR. The microbiology of impetigo in indigenous children: associations between Streptococcus pyogenes, Staphylococcus aureus, scabies, and nasal carriage. BMC Infect Dis. 2014;14:727.

62. Steer AC, Jenney AW, Kado J, et al. High burden of impetigo and scabies in a tropical country. PLoS Negl Trop Dis. 2009;3(6):e467. 
63. Shaw K, Smith S, Driscoll M. Scabies herpeticum: crusted scabies with herpes simplex superinfection. G Ital Dermatol Venereol. 2017;152(2): 192-193.

64. Ackerman AB, Stewart R, Stillman M. Scabies masquerading as dermatitis herpetiformis. JAMA. 1975;233(1):53-54.

65. Gunaric A, Jurisic K, Simic D, Penavic JZ, Jozic S, Goluza I. Scabies mimicking child abuse - a case report. Psychiatr Danub. 2017;29(Suppl 2): 143-147.

66. Yang YS, Brun YS, Kim JH, Kim HO, Park CW. Infantile scabies masquerading as Langerhans cell histiocytosis. Ann Dermatol. 2015;27(3):349-351.
67. Aterman K, Krause VW, Ross JB. Scabies masquerading as LettererSiwe's disease. Can Med Assoc J. 1976;115(5):443-444.

68. Bastian HM, Lindgren AM, Alarcon GS. Scabies mimicking systemic lupus erythematosus. Am J Med. 1997;102(3):305-306.

69. Witkowski JA, Parish LC. Scabies: a cause of generalized urticaria. Cutis. 1984;33(3):277-279.

70. Colgecen-Ozel E, Ertas R, Utas S, Kontas O. Scabies mimicking mastocytosis in two infants. Turk J Pediatr. 2013;55(5):533-535.

71. Phan A, Dalle S, Balme B, Thomas L. Scabies with clinical features and positive darier sign mimicking mastocytosis. Pediatr Dermatol. 2009;26(3):363-364.

\section{Publish your work in this journal}

Clinical, Cosmetic and Investigational Dermatology is an international, peer-reviewed, open access, online journal that focuses on the latest clinical and experimental research in all aspects of skin disease and cosmetic interventions. This journal is included on PubMed. The manuscript management system is completely online and includes a very quick and fair peer-review system, which is all easy to use. Visit http://www.dovepress.com/testimonials.php to read real quotes from published authors 